\title{
PELATIHAN ELEKTRONIKA DASAR GUNA MEMBUKA PELUANG KEWIRAUSAHAAN WARGA DESA RANCAGONG KECAMATAN LEGOK KABUPATEN TANGERANG
}

\author{
Toni $^{1}$, Muh. Wildan ${ }^{2}$, Sabdo Purnomo ${ }^{3}$, Johan Wahyudi ${ }^{4}$, Oka Fatra ${ }^{5}$ \\ 1) toni@ppicurug.ac.id*, Politeknik Penerbangan Indonesia Curug, Tangerang \\ 2) muh.wildan@ppicurug.ac.id, Politeknik Penerbangan Indonesia Curug, Tangerang \\ 3) sabdo.purnomo@ppicurug.ac.id, Politeknik Penerbangan Indonesia Curug, Tangerang \\ 4) johan.wahyudi@ppicurug.ac.id, Politeknik Penerbangan Indonesia Curug, Tangerang \\ 5) oka.fatra@ppicurug.ac.id, Politeknik Penerbangan Indonesia Curug, Tangerang \\ * untuk penulis korespondensi
}

\begin{abstract}
Changing times require people to be able to keep up with technological developments. One of technologies that plays a big role in changing people's patterns and lifestyles are electronic technology. The development of electronic technology requires human resources who have competencies that are in accordance with the needs of society and industri. Based on observation survey had been done to Rancagong people, they haven't understand about electronic too much. So that it's worth to be done the community service at the location. Several subject matters are soldering practice, led assembly: seri and parallel, led blinking assembly, assembly of lighting sensors automatically and amplifier assembly. Implementation of community service involve lecturers/intructors as embodiment in college obligations. In addition, this activity also involves students in order to get experiences and lesson learned directly.
\end{abstract}

Keywords : technology, electronic, entrepreneurship

\begin{abstract}
Abstrak
Perubahan zaman menuntut masyarakat untuk dapat lebih mengikuti perkembangan teknologi. Salah satu teknologi yang memegang peranan sangat besar dalam mengubah pola dan gaya hidup masyarakat adalah teknologi elektronika. Berkembangnya teknologi elektronika tentunya membutuhkan sumber daya manusia yang memiliki kompetensi yang sesuai dengan kebutuhan masyarakat dan industri. Berdasarkan hasil observasi yang dilakukan terhadap masyarakat Desa Rancagong, belum banyak masyarakat yang mengerti di bidang elektronika sehingga layak untuk dilakukan kegiatan pengabdian masyarakat di lokasi tersebut. Dalam kegiatan pengabdian kepada masyarakat ini dilakukan beberapa hal yang akan menjadi solusi permasalahan yang ada di Desa Rancagong guna membuka peluang kewirausahaan, diantaranya pelatihan praktek penyolderan, perakitan rangkaian LED seri dan pararel, perakitan rangkaian blinking LED, perakitan rangkaian sensor cahaya otomatis dan merakit amplifier. Pelaksanaan kegiatan ini melibatkan dosen/instruktur sebagai wujud dharma perguruan tinggi. Selain itu kegiatan ini juga melibatkan taruna/taruni sebagai pengalaman lapangan dan media pembelajaran secara langsung.
\end{abstract}

Kata Kunci : teknologi, elektronika, kewirausahaan

\section{PENDAHULUAN}

Kebutuhan tenaga untuk memperbaiki dan merawat peralatan elektronika masih terbuka sangat luas. Bengkel-bengkel perbaikan elektronika hingga industri membutuhkan tenaga teknisi elektronika untuk perawatan dan perbaikan peralatan elektronika di berbagai industri (Amri \& Stephan, 2019; Atmam, Zulfahri, \& Situmeang, 2018; Djoko, Indarto, \& Santoso, 2019; Krismadinata, Anwar, \& Akbar, 2021; Porawati, Sepdian, Isnen, Novarini, \& Yaakub, 2019; Rahmatia \& Arifianto, 2017; Risnandar, Sambas, \& Ula, 2019; Saleh, Darwis, \& Arhas, 2021; Syaifurrahman;, Tjahjamooniarsih, Suryadi, Saleh, \& Elbani, 2021; Waryanto, Marwoto, Hernawati, Emut, \& Insani, 2017). Berdasarkan data dari Desa Rancagong, Kecamatan Legok, memiliki jumlah penduduk 13.465 orang dengan warga/pemuda usia produktif antara $17-60$ tahun yang masih belum mendapatkan pekerjaan kurang lebih sekitar 9.896 orang sehingga potensi / peluang untuk berkarya dan menjadi seorang teknisi di dalam dunia bidang elektronika masih sangat besar.

Pengabdian masyarakat merupakan suatu media yang menghubungkan dunia pendidikan dengan masyarakat sekitar (Kalbuana et al., 2021; Prasetyo, Rohman, Solihin, 
Sundoro, \& Kalbuana, 2021; Sihono, Fatkulloh, et al., 2021). Politeknik Penerbangan Indonesia Curug akan memberikan kegiatan berupa pelatihan kepada masyarakat sebagai bentuk hilirisasi pengajaran beberapa matakuliah yang dapat dirasakan manfaatnya oleh Masyarakat disekitar kampus PPI Curug (Arnas et al., 2021; Sihono, Fatkhulloh, Saputro, Herwanto, \& Kalbuana, 2021), khususnya warga Desa Rancagong, Kecamatan Legok. Kab. Tangerang. PKM merupakan bentuk tridharma perguruan tinggi juga sebagai wujud nyata kepedulian PPI Curug dalam meningkatkan pengetahuan dan ketrampilan masyarakat di sekitar kampus. Terlebih pada saat ini kondisi bencana pandemi covid-19, perlu dituntut semangat kewirausahaan/ entrepreneurship untuk menopang kehidupan dan meningkatkan taraf ekonomi masyarakat.

\section{METODE}

Kegiatan pengabdian kepada masyarakat yang dilaksanakan oleh para dosen PPI Curug yang memiliki latar belakang kompetensi bidang elektronika dasar, diselenggarakan secara tatap muka kepada para pemuda/i Desa Rancagong dengan tetap mengedepankan protokol kesehatan yang berlaku di masa pandemi covid-19. Tahapan pelaksanaannya adalah sebagai berikut.

\section{Tahap Persiapan}

Pada tahap ini beberapa aktivitas pengabdian kepada masyarakat yang dilakukan dengan melakukan koordinasi dengan unit terkait dan perangkat Desa Rancagong, mempersiapkan kelengkapan administrasi, mempersiapkan alat-alat/komponen elektronika yang akan digunakan untuk pelatihan, mempersiapkan modul/materi dasar elekronika serta melakukan pendekatan/interaksi dengan masyarakat desa rancagong.

\section{Tahap Pelaksanaan}

Pelaksanaan kegiatan dilangsungkan selama 3 (tiga) hari, mulai tanggal 14 sampai dengan 16 Oktober 2021. Pelaksanaan hari pertama, Kamis 14 Oktober 2021 diawali dengan pelaksanaan antigen bagi peserta pelatihan. Dilanjutkan dengan Acara Pembukaan kegiatan PKM, dibuka oleh Wakil Direktur III PPI serta dihadiri oleh seluruh Tim Dosen/Pengajar dan Staf Prodi TNU, Perwakilan dari Pusat PPM PPI Curug dan Kepala Desa Rancagong beserta Staf. Setelah acara pembukaan, kegiatan PKM ini dilanjutkan dengan pembahasan Materi Elektronika Dasar antara lain Pengenalan Komponen Elektronika.

Pelaksanaan Hari Kedua, Jumat 15 Oktober 2021 dilaksanakan dengan pemberian materi pelatihan yang diberikan kepada para peserta berupa praktek penyolderan, perakitan rangkaian LED seri dan pararel, perakitan rangkaian blinking LED serta perakitan rangkaian sensor cahaya otomatis.

Pelaksanaan hari ketiga, Sabtu 16 Oktober 2021, diisi dengan kegiatan merakit Amplifier dilanjutkan demo alat oleh perwakilan peserta di hadapan Wakil Direktur III dan Pejabat yang mewakili Kepala Desa Desa Rancagong. Setelah selesai melaksanakan Rangkaian Pelatihan Dasar Elektronika Peserta diberikan bekal Peralatan yang bertujuan agar dapat di aplikasikan dikehidupan bermasyarakat dan Kegiatan Pelatihan Dasar Elektronika secara resmi ditutup oleh wakil Direktur III PPI Curug yang dihadiri oleh Kepala Pusat PPM PPI Curug dan dihadiri oleh Pejabat yang mewakili Kepala Desa Rancagong.

\section{Tahap Pelaporan}

Pada tahap ini, aktivitas yang dilakukan adalah demonstrasi hasil yang telah dipraktekkan oleh peserta pelatihan yang diwakili oleh salah seorang peserta. Demonstrasi dilaksanakan pada hari ketiga dan peserta diberi kesempatan untuk menguraikan proses merakit dan implementasi hasil. Bagi para Dosen/Instruktur yang ikut serta sebagai Pelaksana dharma perguruan tinggi, pelaporan dihasilkan dalam bentuk naskah laporan serta jurnal yang dipublikasi. 


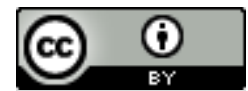

\section{HASIL DAN PEMBAHASAN}

Kegiatan PKM pada hari pertama diawali dengan pelaksanaan antigen bagi perserta pelatihan dengan hasil semua peserta negative dilanjutkan dengan acara pembukaan mulai pukul 09.00 WIB. Pembukaan kegiatan PKM dibuka oleh Wakil Direktur III PPI Curug Bapak RB. Budi Kartika W, S.Pd., S.SiT., MT dan dihadiri oleh seluruh Tim Dosen/Pengajar dan Staf Prodi TNU, Perwakilan dari Pusat PPM PPI Curug dan Kepala Desa Rancagong beserta Staf. Dalam sambutannya Wakil Direktur III menyampaikan penghargaan kepada tim PKM Prodi TNU dan Pihak Desa Rancagong yang telah melaksanakan salah satu dari kegiatan Tri Dharma Perguruan Tinggi terutama di sekitar lingkungan kampus PPI Curug. Selanjutnya sambutan dari Kepala Desa Rancagong Bapak Iwan Patiwel yang dalam sambutannya menyampaikan ucapan terima kasih kepada pihak PPI Curug atas kerjasama dan kepeduliannya kepada warga masyarakat Desa Rancagong.

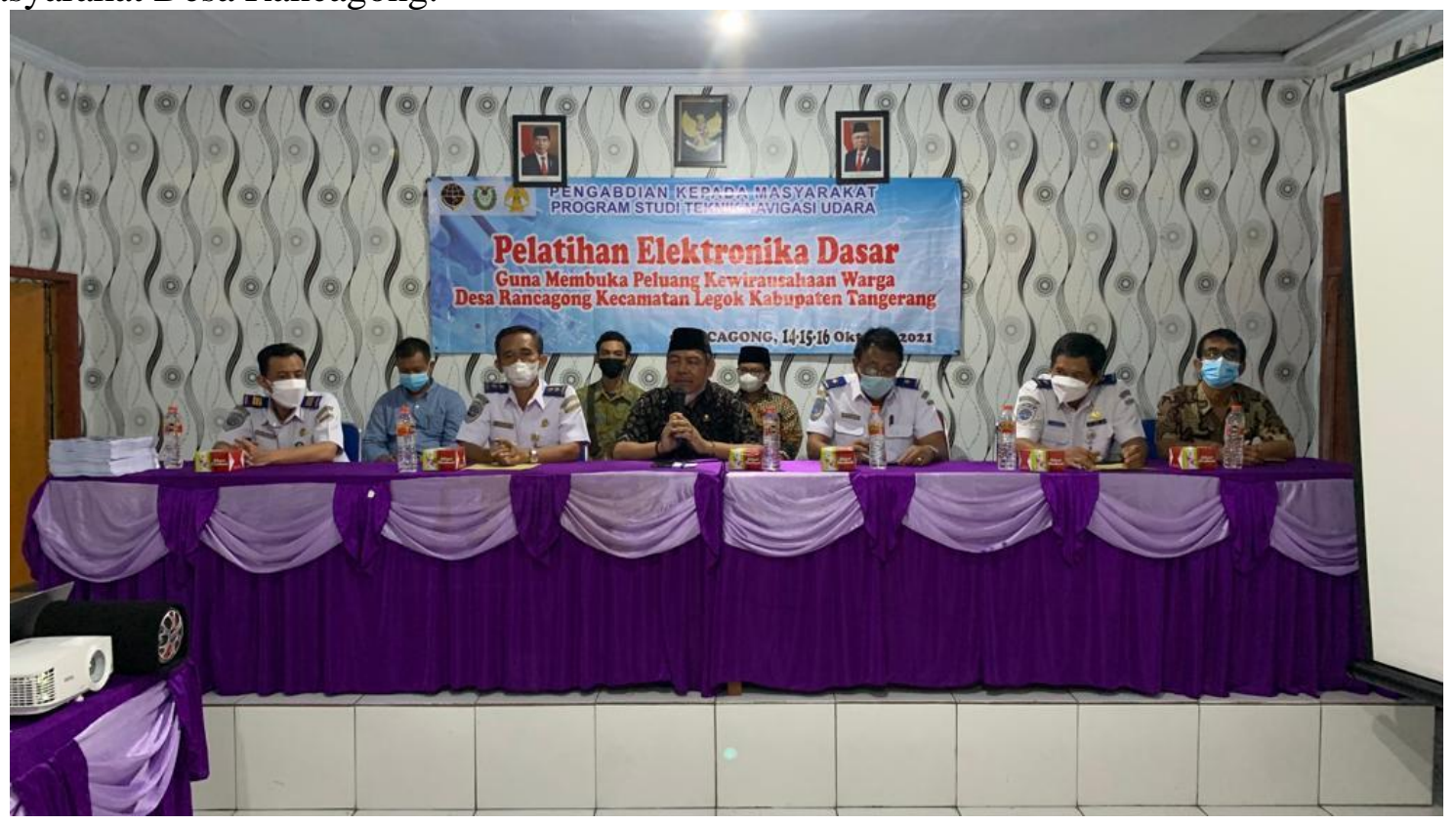

Gambar 1

Acara Pembukaan PkM oleh Wakil Direktur III PPI Curug (baris depan nomor dua dari kiri)

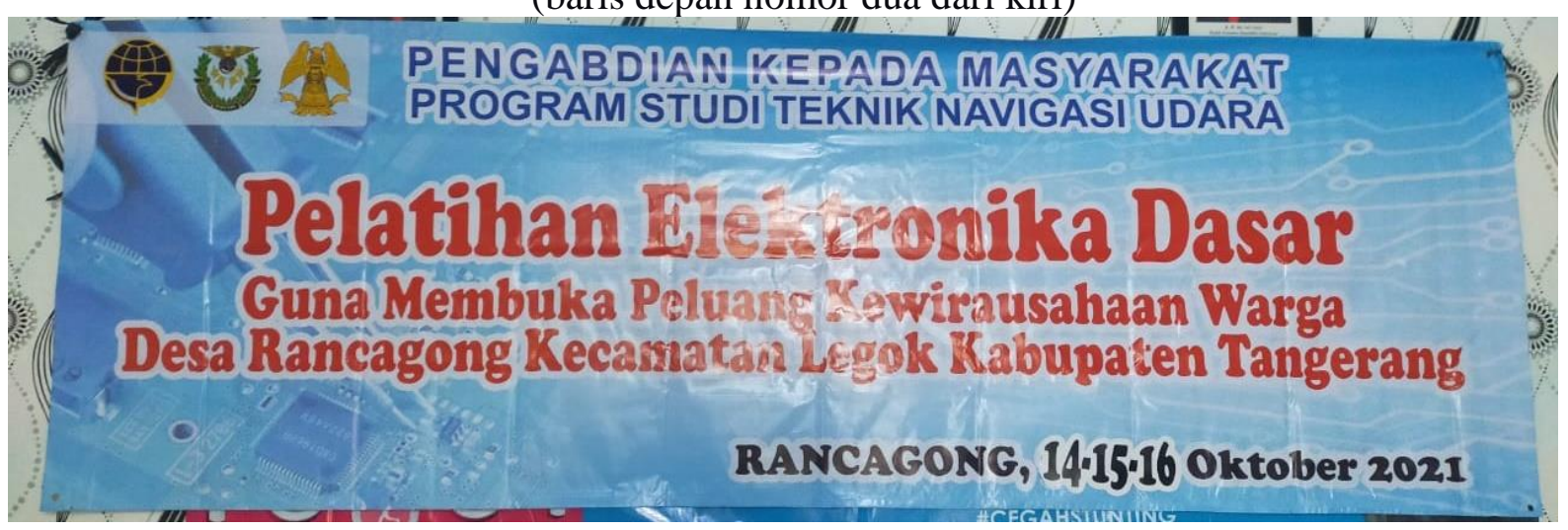

Gambar 2

Spanduk Kegiatan PkM Pelatihan Elektronika Dasar 


\section{PENGMASKU}

Volume 2 No. 1, 2022

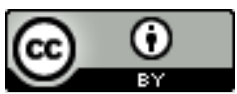

Setelah acara pembukaan, kegiatan PKM ini dilanjutkan dengan pembahasan teori Elektronika Dasar antara lain Pengenalan Komponen Elektronika seperti Resistor (Tetap dan Variabel), Kapasotor, Induktor, Bioda, Transistor dan IC dan Alat Ukur yaitu AVO Meter Analog dan Digital untuk mengukur tegangan, mengukur nilai resistor, kapasitor, continuity, dioda, transistor oleh Tim Dosen/Tim Pengajar.

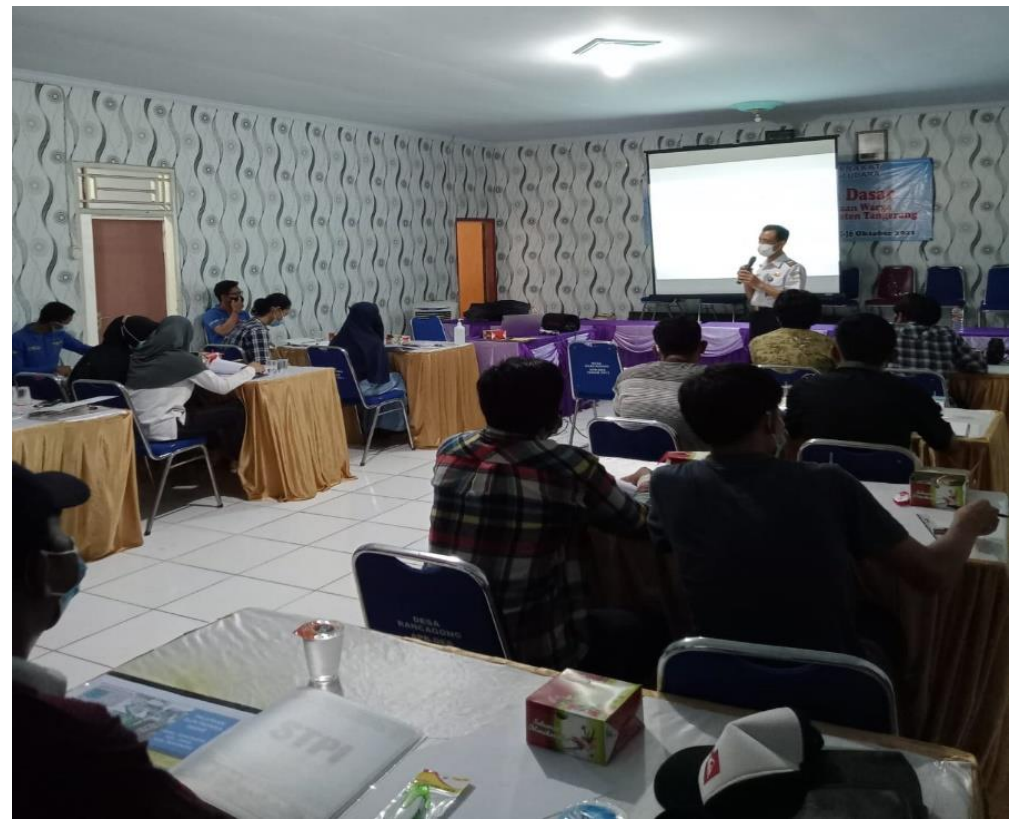

Gambar 3

Materi Pengenalan Komponen, Toolkit dan Alat Ukur

Pada hari kedua pelaksanaan kegiatan PKM yang dilakukan oleh para peserta pelatihan meliputi: praktek penyolderan, perakitan rangkaian LED seri dan pararel, perakitan rangkaian Blinking LED dan perakitan rangkaian Sensor Cahaya Otomatis.

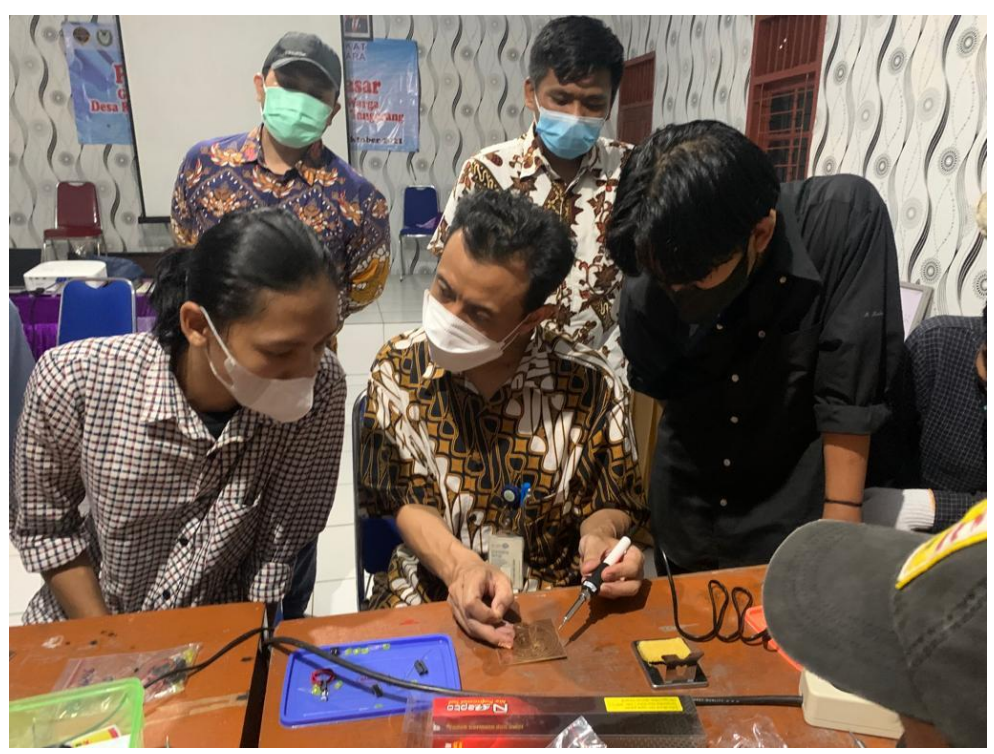

Gambar 4

Praktek Penyolderan Dalam Rangka Perakitan Rangkaian LED 


\section{PENGMASKU}

Volume 2 No. 1, 2022

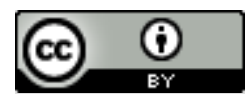

Gambar 4 menampilkan praktek penyolderan oleh salah seorang Dosen kepada para peserta pelatihan. Kegiatan ini merupakan aktivitas yang dilakukan pada hari kedua, sebelum masuk pada pelatihan merakit beberapa rangkaian LED. Tampak pada Gambar 3.4 para peserta menyimak penjelasan oleh Dosen dengan seksama mengenai prosedur dan cara kerja solder serta penggunaan alat dan bahan dalam penyolderan. Salah satu tangan (tangan kanan) Dosen memegang bahan timah dan tangan yang lain (tangan kiri) memegang alat solder. Posisi kedua lata dan bahan perlu menjadi perhatian peserta agar hasil yang diperoleh setelah melakukan praktek penyolderan optimal. Kesalahan dalam memposisikan alat dan bahan pada waktu penyolderan dapat mengakibatkan kegagalan kerja rangkaian.

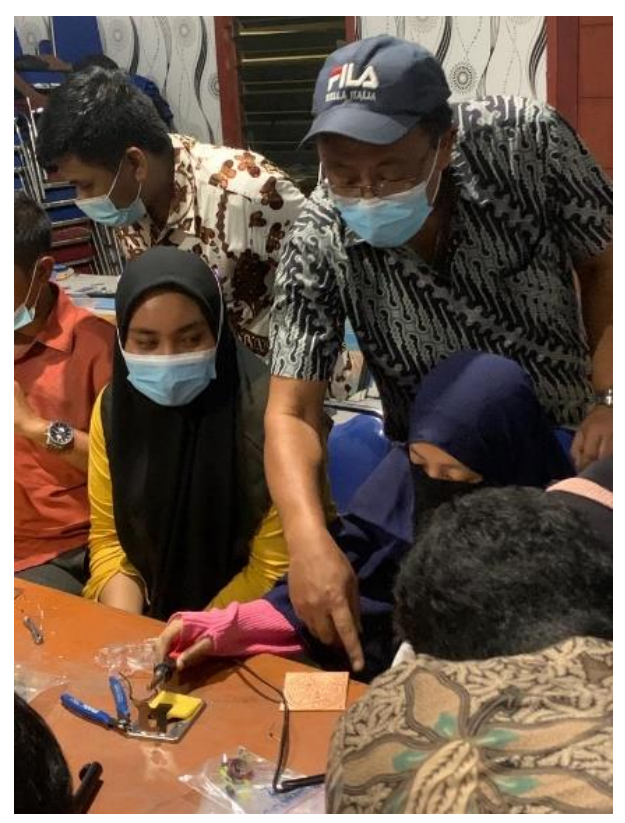

Gambar 5

Perakitan Rangkaian LED Seri, Paralel dan Blinking LED

Gambar 5 merupakan penjelasan mengenai prosedur dan cara merakit rangkaian LED seri, paralel dan blinking LED oleh Dosen kepada peserta pelatihan. Sebelum merakit, peserta diberikan paket berupa bahan yang dapat menghasilkan kerja rangkaian LED, di antaranya PCB (Printed Circuit Board), lampu LED, kapasitor dan resistor. Selanjutnya, dengan menggunakan lembar kerja yang disertai dengan penjelasan gambar rakitan, Dosen memberi petunjuk kepada peserta bagaimana memperlakukan bahan yang telah diberikan sehingga tersusun sebagai rangkaian yang siap di-solder. Perlu ketelitian masing-masing peserta pelatihan agar mendapatkan hasil rangkaian LED seri, paralel dan blinking agar target pencapaian pelatihan di hari kedua tercapai. 


\section{PENGMASKU}

Volume 2 No. 1, 2022
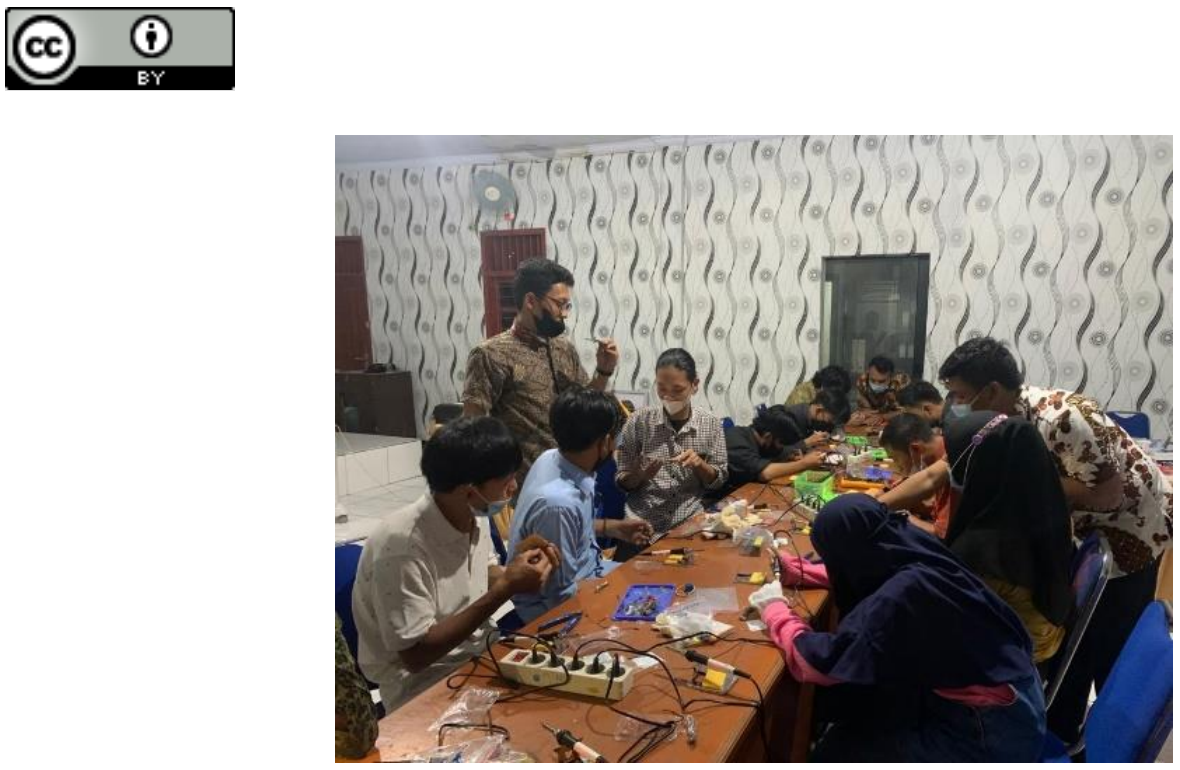

Gambar 6

Pendampingan Perakitan Rangkaian LED Seri, Paralel dan Blinking LED bagi

Peserta yang Belum Mencapai Target Penyelesaian

Gambar 6 menunjukkan pendampingan yang dilakukan oleh beberapa Instruktur kepada para peserta pelatihan yang memerlukan penjelasan serta cara penyusunan rangkaian LED lebih rinci karena dibatasi oleh waktu. Dalam hal ini, peserta semakin antusias mengikuti pelatihan di hari kedua dan bersemangat untuk menyelesaikan target tepat waktu. Bagi peserta pelatihan yang telah menyelesaikan materi pada hari kedua, diberi kesempatan untuk mendampingi peserta yang lain agar pemahaman dan implementasi praktek merakit dan menyelesaikan tugas sesuai target.

Pada hari ketiga, kegiatan PkM diakhiri dengan merakit Amplifier dilanjutkan demo alat oleh perwakilan peserta di hadapan Wakil Direktur III dan pejabat yang mewakili Kepala Desa Desa Rancagong. Setelah selesai melaksanakan Rangkaian Pelatihan Dasar Elektronika pada hari Sabtu tanggal 16 Oktober 2021 pukul 15.00 WIB, masing-masing peserta pelatihan diberikan sertifikat dan peralatan antara lain AVO Meter, Solder, komponen elektronika(tambahan) dan toolkit yang bertujuan agar dapat diaplikasikan di kehidupan bermasyarakat.

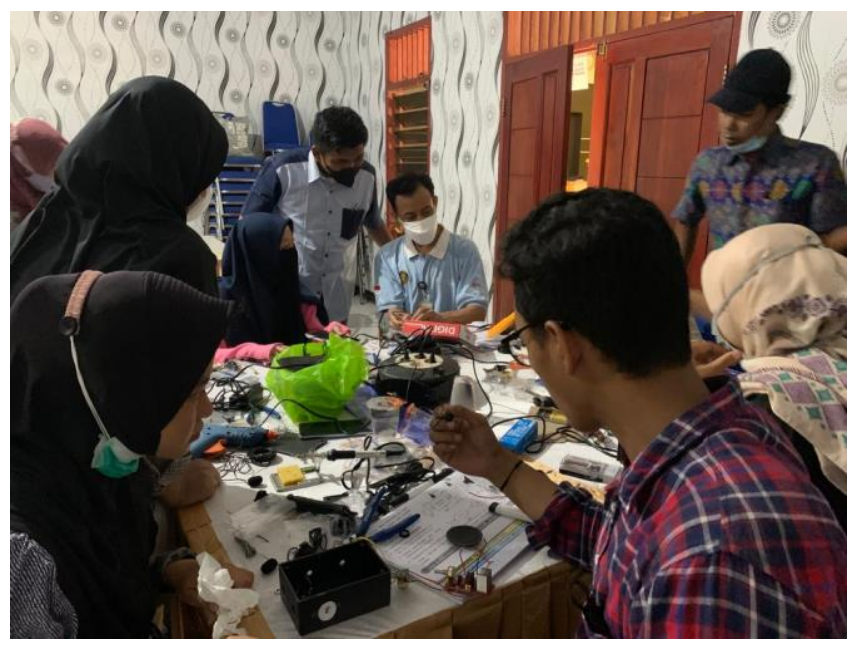

Gambar 3.7

Perakitan Rangkaian Amplifier di Hari Ketiga 


\section{PENGMASKU}

Volume 2 No. 1, 2022
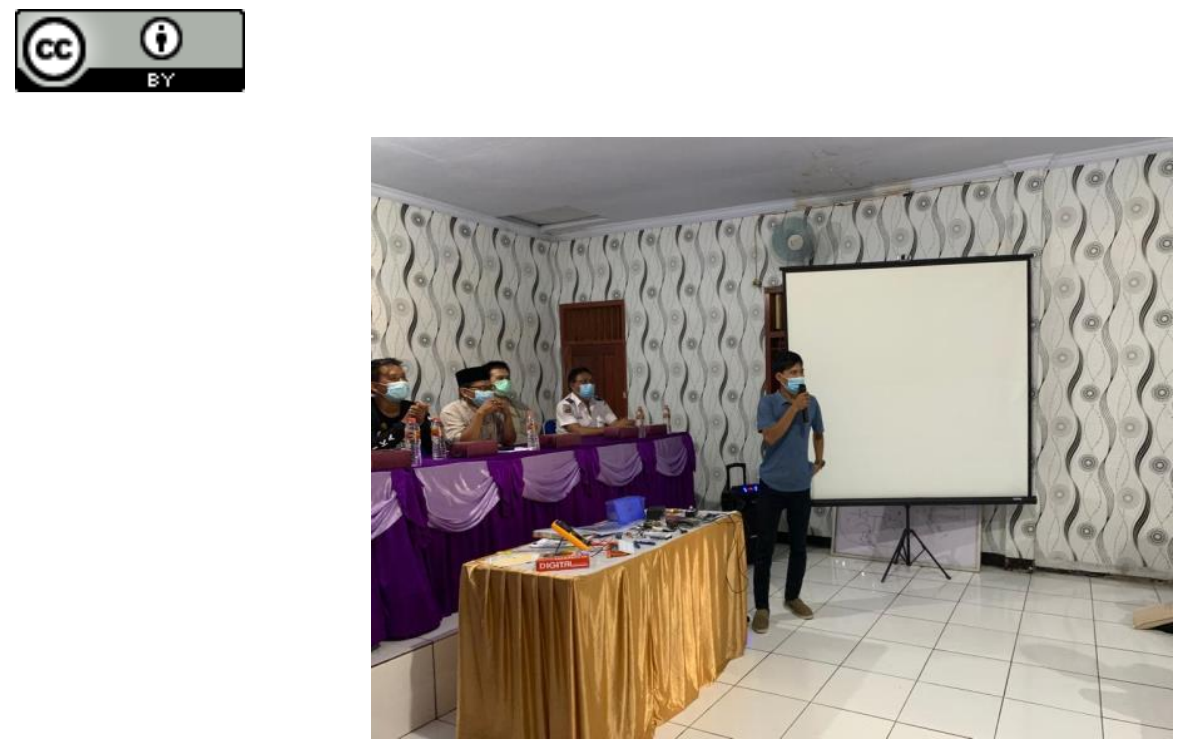

Gambar 8

Perwakilan Peserta Mendemonstrasikan Hasil Pelatihan di Hari Ketiga

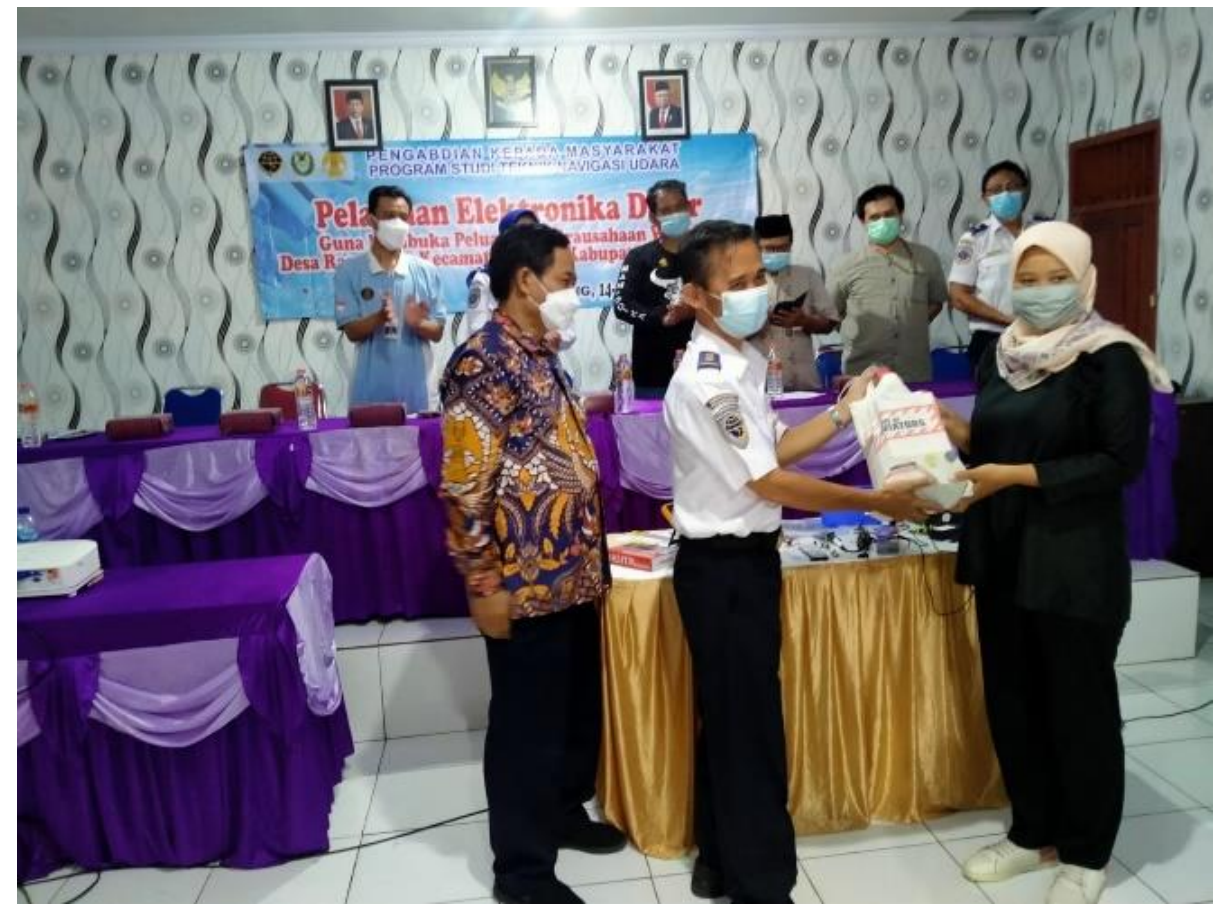

Gambar 9

Pemberian Sertifikat Beserta Alat dan Bahan Komponen Elektronika kepada Perwakilan Peserta Pelatihan Secara Simbolis

Kegiatan Pelatihan Dasar Elektronika secara resmi ditutup oleh Wakil Direktur III PPI Curug yang dihadiri oleh pejabat, baik dari PPI Curug maupun Desa Rancagong serta Dosen/Instruktur. 

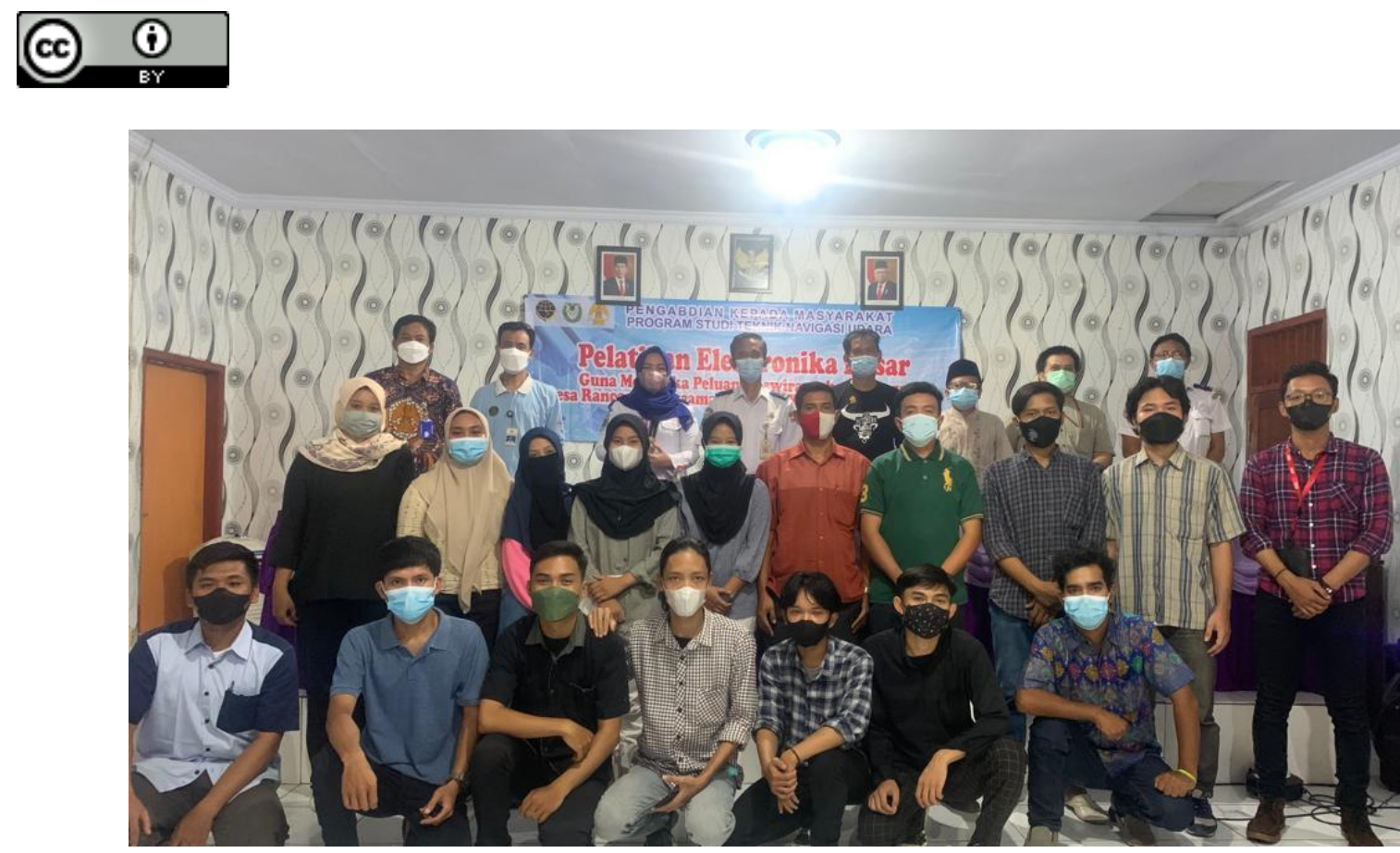

Gambar 10

Foto Bersama Wakil Direktur III, Para Pejabat PPI Curug dan Desa Rancagong, Dosen/Instruktur serta Seluruh Peserta Pelatihan Dasar Elektronika

\section{PENUTUP}

\section{Simpulan}

Pelatihan Dasar Elektronika yang diadakan untuk para pemuda/i di Desa Rancagong selama 3 (tiga) hari diperoleh hasil-hasil positif yang dapat dimanfaatkan oleh mereka sebagai peserta pelatihan, yaitu mengetahui bentuk dan cara kerja komponen elektronika dan alat kerja yang berfungsi untuk mengukur dan menyolder. Selanjutnya, implementasi terhadap beberapa rangkaian, yaitu LED dan amplifier dapat memberikan wawasan kepada peserta pelatihan mengenai arti penting sebuah usaha dan kewirausahaan.

\section{Penghargaan}

Penghargaan yang tinggi kami berikan kepada Kementerian Perhubungan RI, Badan Pengembangan SDM Perhubungan, Pusat Pengembangan SDM Perhubungan Udara dan khusus kepada Direktur Politeknik Penerbangan Indonesia Curug melalui Pusat Penelitian dan Pengabdian kepada Masyarakat atas dana hibah PKM yang diperoleh sehingga bisa menyelenggarakan kegiatan ini dengan normal dan tepat waktu.

\section{DAFTAR PUSTAKA}

Amri, H., \& Stephan. (2019). Pelatihan Reparasi Peralatan Elektronik Rumah Tangga (Lampu Penerangan LED). Kumawula: Jurnal Pengabdian Kepada Masyarakat, 2(3), 192-200. https://doi.org/10.24198/kumawula.v2i3.24514

Arnas, Y., Ismail, K. G. S. M., Kurniawati, Z., Kurnianto, B., Wibowo, I. H., \& Kalbuana, N. (2021). Pelatihan perawatan / service AC untuk masyarakat sekitar Politeknik Penerbangan Indonesia Curug. Penamas: Journal of Community Service, 1(2), 90-99.

Atmam, Zulfahri, \& Situmeang, U. (2018). Pelatihan Penggunaan Komponen Dioda Pada Rangkaian Elektronika Bagi Mahasiswa Fakultas Ilmu Komputer Universitas Lancang Kuning Pekanbaru. Dinamisia : Jurnal Pengabdian Kepada Masyarakat, 2(1), 124-128. https://doi.org/10.31849/dinamisia.v2i1.1151 
Djoko, S., Indarto, \& Santoso, A. (2019). Pelatihan Pemasaran Elektronik Bagi Usaha Kecil Difabel. Pelatihan Pemasaran Elektronik Bagi Usaha Kecil Difabel, 01(01), 18-22.

Kalbuana, N., Hendra, O., Aswia, P. R., Lestary, D., Kardi, \& Solihin. (2021). Pengenalan Unit Penanggulangan Keadaan Darurat Di Bandara Bagi Siswa SMK Penerbangan di Wilayah Lampung dan Sidoarjo. Jubaedah : Jurnal Pengabdian dan Edukasi Sekolah, $1(3), 232-239$.

Krismadinata, Anwar, \& Akbar, J. (2021). Pengembangan Training Kit Pada Mata Pelajaran Mengoperasikan Sistem Kendali Elektronik. Jurnal Pendidikan Teknologi dan Kejuruan, 18(1), 89-98.

Porawati, H., Sepdian, Isnen, M., Novarini, \& Yaakub, S. (2019). Pelatihan Dasar ElektronikaListrik dan Pengenalan Bahan KBR Pada Detasemen Gegana Satuan Brimob Kepolisian Daerah Jambi. Suluh Abdi: Jurnal Ilmiah Pengabdian Kepada Masyarakat, $1(1), 25-30$.

Prasetyo, B., Rohman, T., Solihin, S., Sundoro, S., \& Kalbuana, N. (2021). Sosialisasi Kawasan Keselamatan Operasi Penerbangan (KKOP). Jurnal Pengabdian Kepada Masyarakat (JPKM) Langit Biru, 2(1), 31-38. https://doi.org/10.54147/JPKM.V2I01.451

Rahmatia, S., \& Arifianto, I. (2017). Pelatihan Dasar Flip-Flop untuk SMA/SMK dan Sederajat. JURNAL Al-AZHAR Indonesia Seri Sains dan Teknologi, 4(2), 58-60. https://doi.org/10.36722/sst.v4i2.256

Risnandar, M. A., Sambas, A., \& Ula, S. (2019). PKM Pelatihan Perakitan Elektronika Sebagai Bekal Keterampilan Generasi Milenial Di Kota Tasikmalaya. Martabe: Jurnal Pengabdian Masyarakat, 2(2), 78-84.

Saleh, S., Darwis, M., \& Arhas, H. (2021). Pelatihan Pembuatan Dan Penggunaan Media Pembelajaran Berbasis Elektronik dan Non-Elektronik. JMM (Jurnal Masyarakat Mandiri), 5(1), 73-80.

Sihono, S., Fatkhulloh, A., Saputro, R., Herwanto, D., \& Kalbuana, N. (2021). Pendalaman Buku Ajar Elektrikal dan Elektronika Pesawat Udara Bagi Guru SMK Penerbangan. Jurnal Pengabdian Kepada Masyarakat (JPKM) Langit Biru, 2(1), 46-54. https://doi.org/10.54147/jpkm.v2i01.462

Sihono, S., Fatkulloh, A., Saputro, R., Herwanto, D., Kalbuana, N., \& Kurnianto, B. (2021). Pemantapan Dan Refreshing Materi Electrical \& Electronik Untuk Guru Smk Penerbangan Di Jawa Tengah Dan Sekitarnya. Jubaedah: Jurnal Pengabdian dan Edukasi Sekolah (Indonesian Journal of Community Services and School Education), 1(1), 12-19. https://doi.org/10.46306/jub.v1i1.2

Syaifurrahman;, Tjahjamooniarsih, N., Suryadi, D., Saleh, M., \& Elbani, A. (2021). Pelatihan Elektronika Dasar Bagi Siswa Sekolah Menengah Atas di Wilayah Kalimantan Barat. Jurnal Pengabdi, 4(2), 185. https://doi.org/10.26418/jplp2km.v4i2.48106

Waryanto, N. H., Marwoto, B. S. H., Hernawati, K., Emut, E., \& Insani, N. (2017). Pelatihan Pembuatan Buku Elektronik Interaktif. Jurnal Pengabdian Masyarakat MIPA dan Pendidikan MIPA, 1(1), 33-40. https://doi.org/10.21831/jpmmp.v1i1.12971 